I Pontifícia Universidade Católica do Rio de Janeiro (PUC-Rio), Programa

de Pós-Graduação em Comunicação, Rio de Janeiro, RJ, Brasil

claudiapereira@puc-rio.br

https://orcid.org/0000-0002-5382-130X

I IUniversidade de Brasília (UnB), Programa de Pós-Graduação em

Comunicação, Brasília, DF, Brasil

Cláudia Pereira'

nandamartineli@yahoo.com.br

https://orcid.org/000o-0002-0196-048X

Fernanda Martinelli"

\title{
AS PESSOAS, AS COISAS E AS PERDAS: PERSPECTIVAS DA CULTURA MATERIAL E DO CONSUMO NOS ESTUDOS DE DANIEL MILLER
}

\author{
As pessoas existem para nós em e por meio de \\ sua presença material ${ }^{1}$ \\ Daniel Miller
}

Tinha tudo sob controle: sua rotina regrada, seu corpo, seus sentimentos, seus relacionamentos, sua mesa de escritório na sala. Tudo estava conforme o esperado, nada fora do lugar. Um dia, pela janela de sua casa, sempre aberta para os dias de sol, avançou um vento muito forte, imprevisível, que primeiro sacudiu a cortina, que fez tombar a luminária, estilhaçando a lâmpada em mil pedaços, e que depois percorreu toda a casa, cômodo por cômodo, derrubando bibelôs, desfolhando as plantas, espalhando as pétalas secas perfumadas pela mesinha de centro, agitando as folhas do livro aberto na mesa de cabeceira, levando ao chão a correspondência recém-resgatada da caixa de correios. Fazendo a volta pelo corredor, depois de adentrar os quartos, antes de perder sua força, o vento deixou o tapete do escritório todo coberto com as mais de roo folhas de papel recém-impressas - e que agora, espalhadas, deixavam sem sentido os números das páginas -, suas canetas multicoloridas e as fotografias antigas que estava separando a fim de levar para sua irmã. Saiu correndo da cozinha, assustada com a súbita visita desse vento de verão, deparou-se com a bagunça que de repente se instalara em seus espaços e, primeiro, imobilizouse, depois sentiu raiva pela desordem, em seguida entristeceu, resignou-se e, só mais tarde, pôs-se a rearranjar as coisas que restaram, resmungando e lamentando o que se perdera.

Metáforas e eufemismos são figuras de linguagem sempre bem-vindas, mesmo quando o discurso se pretende sociológico e científico. Como José Machado Pais (I993, p. I3) já pontuou, "No discurso científico, a metáfora desem- 
penha também uma função de transporte - transporte de ideias - para melhor as fazer chegar a bom termo, a bom porto. Deste modo, a metáfora não é reduzível a ornamento. É também um meio de redescrever a realidade". Quando tentamos abordar temas que podem trazer algum tipo de ruptura na ordem que estabelecemos para nossas vidas diárias, tal qual o vento inesperado que entra violento pela janela da casa, a metáfora nos chega a bom termo. A morte de pessoas que amamos, para a maioria de nós, é um desses temas disruptivos. De repente, vemos nossa vida tão desordenada e sem sentido como o tapete da sala de estar. Mas há também outros tipos de morte, não de pessoas, mas de coisas ou de um conjunto de coisas, que nos levam a um sentimento de luto, aquele que primeiro nos paralisa, depois nos leva à revolta ou indignação, em seguida à tristeza, resignação e reconstrução. Em meio a esse processo, passamos a nos posicionar como sujeitos que somos diante de uma nova realidade e isso fazemos, não raro, reordenando, rearranjando e ressignificando as materialidades ou o que delas restou, para que possamos, enfim, nos tornar outra pessoa, que se reconfigura diante de uma nova ordem.

O objetivo deste artigo é enfatizar a construção ontológica que se dá entre pessoas e coisas, coisas e pessoas, para além das trocas simbólicas, coletivas e públicas, promovida pelo consumo. Para tanto, propomos uma reflexão sobre relações que as pessoas estabelecem com as coisas em situações de luto, expressão que usaremos aqui referindo-nos não somente ao sentimento associado à morte de pessoas, mas ampliando seu significado para um sentimento de perda de determinadas materialidades.

A abordagem das teorias de Daniel Miller, antropológica e etnográfica, que se concentra nas relações dialéticas entre pessoas e coisas, e entre coisas e pessoas, é o que sustenta as ideias propostas neste texto. Dois de seus livros, Material culture and mass consumption, de I987, e The comfort of things, de 2008, nos inspiram na discussão sobre a concepção maior dos estudos da "cultura material" no campo da antropologia do consumo.

Em sua obra de I987, Miller elabora o que se tornaria, a partir de então, sua teoria geral sobre a cultura material e sobre o consumo, apresentando-nos a conceitos importantes para a compreensão de seus textos, como "objetificação", "humildade dos objetos" e "poder da agência", os quais serão explorados adiante.

Mais tarde, em 2008, o autor nos oferta outro texto, menos formal e cheio de densidade teórica, que busca fazer conhecer de que modo os londrinos residentes em uma rua da cidade - muitos deles não ingleses - se relacionam com seus objetos. Batendo de porta em porta, o antropólogo escolhe 30 retratos - no original, portraits - de pessoas, de uma centena delas, algumas vivendo sozinhas e outras em família, que estabelecem diferentes tipos de "relacionamentos" com os objetos que possuem dentro de suas casas, cada uma em sua cosmologia e diversidade muito próprias, mas que, todas juntas, levam-nos a 
compreender as sociedades em que vivemos. Cabe aqui antecipar que Miller entende o termo "objeto" de modo bastante amplo, o que inclui vasos, por exemplo, mas também cachorros. Aprendemos, com os portraits de Miller (2008, p. 286), que os objetos materiais são vistos como parte integrante e inseparável dos relacionamentos, aspecto que é central para a vida moderna - e, mais que isso, o autor defende a centralidade da cultura material para os relacionamentos que colecionamos ao longo da vida. De acordo com ele, há um ordenamento que diz respeito às coisas que nos cercam e, por consequência, aos relacionamentos que mantemos. Essa ordem, que em seu livro Miller chama de "estética", é que conduz as pessoas para a socialização, quando então tomamos as categorias sociais para afirmar quem somos e quem é o outro. Dos 30 portraits, escolhemos um, o de Elia, para nos ajudar a pensar de que modo as coisas e as pessoas se relacionam, em sentido estrito, para além da esfera das trocas simbólicas e, portanto, públicas e coletivas do consumo.

$\mathrm{Na}$ primeira seção do artigo, trazemos breve síntese da teoria de Daniel Miller, destacando alguns conceitos importantes para a compreensão de nosso ponto de vista e uma discussão sobre a relação entre consumo e cultura material. Na segunda seção, apresentamos um olhar etnográfico de Miller sobre o caso de Elia e o relato de Walter Benjamin sobre seus livros, buscando compreender de que modo se dá o poder de agência dos objetos em contextos de mudança de vida.

\section{O LUTO À LUZ DA CULTURA MATERIAL EM DANIEL MILLER}

Antes de entrar na discussão mais específica sobre o luto, apresentamos breve panorama do universo intelectual que orienta nossas reflexões para pensar, junto com Miller, os significados das coisas em contextos de perdas. Embora a discussão sobre luto seja pontual nos escritos do autor, sua vasta obra fornece subsídios que elaboram a compreensão das relações entre as perdas e as materialidades, bem como do luto e suas cosmologias. No horizonte da discussão que desenvolvemos aqui estamos, no sentido apontado por Miller e Parrott (2009), menos preocupadas com as causas das perdas do que com o modo como os objetos têm protagonismo simultaneamente na continuidade e no término de relações marcadas pelo luto.

Em Material culture and mass consumption, até o momento ainda sem tradução para o português, Miller (I987) afirma a existência de uma relação dialética entre pessoas e coisas. A preocupação do autor com o estudo das coisas remonta à sua formação em arqueologia, e a partir desse livro adquire contornos que expressam um esforço para pensar como sujeitos e objetos se constituem mutuamente em contextos contemporâneos, marcados em particular pela produção industrial de bens em larga escala. Aqui, nosso interesse recai especificamente sobre o modo como pessoas continuam a significar coisas após sua morte e como os objetos produzidos em larga escala se ressingularizam em 
contextos específicos de perda. Se a morte silencia os objetos em um primeiro momento, sobretudo se se trata de morte inesperada ou não planejada, nos termos de Miller (2013), ela também produz, posteriormente, deslocamentos que evidenciam a autonomia das coisas. A compreensão dessas dinâmicas tensiona o próprio sentido social da herança, como discutiremos mais à frente, pelo reconhecimento de que os objetos armazenam sentidos, absorvem histórias, exalam emoções, sobrevivem a perdas e têm poder de agência.

Antes de Miller, outros intelectuais se dedicaram ao estudo das coisas, e dentre eles destacamos Marshall Sahlins (2003) em "O pensamento burguês", texto originalmente publicado no livro Cultura e razão prática, de I976; Arjun Appadurai (I986) em The social life of things; e Mary Douglas e Baron Isherwood (2004), em O mundo dos bens, cuja edição original é de I979. Sahlins, Appadurai, Douglas e Isherwood, cada qual a seu tempo, registram contribuições fundamentais no sentido de reivindicar a centralidade da cultura nas trocas econômicas e da cultura material em particular no estabelecimento e manutenção de vínculos sociais que não se esgotam nem dependem exclusivamente das atividades comerciais. Já na introdução de Material culture and mass consumption, Miller (I987, p. 3) se coloca ao lado desses autores ao reivindicar o reconhecimento da cultura material como elemento central na organização social da vida moderna, ao mesmo tempo em que afirma ter sido a relação entre sociedade e cultura material notoriamente negligenciada pelos meios acadêmicos ao longo do século XX.

Miller, porém, também se distingue de seus antecessores ao propor um novo olhar sobre o entendimento da cultura material na vida moderna e contemporânea, e talvez nisso resida a grande contribuição de Material culture and mass consumption. Ele introduz seu livro com a argumentação de que, em relação aos conhecimentos de linguística, nossa compreensão da cultura material é extremamente rudimentar (Miller, I987, p. 95). Mas embora adote uma perspectiva dos bens como mediadores de relações sociais, o antropólogo britânico não procura transplantar metodologias da linguística para o estudo dos objetos; antes ancora sua afirmação em constatações etnográficas e fundamenta essa relação entre pessoas e coisas a partir de uma "teoria da objetificação", de inspiração hegeliana.

Segundo Miller, existe uma relação de interdependência ontológica entre pessoas e coisas: pessoas precisam de coisas para ser pessoas, coisas precisam de pessoas para ser coisas. Nessa dinâmica de cocriação da cultura material, nos ensina ele, há, nas materialidades que nos cercam, um poder de agência que nos interpela e, muitas vezes, nos controla, seja no espaço da vida social ou da vida privada. Embora atualmente essa já seja uma perspectiva consolidada no campo da filosofia e, mais especificamente, da fenomenologia, sobretudo em função de Hegel, ela continua a desafiar o campo dos estudos de consumo. 
Podemos mesmo considerar que, para Miller, a materialidade é um atributo não somente das coisas, mas também das relações. O fenômeno do consumo, por sua vez, atribui aos bens materiais o lugar privilegiado de marcadores sociais, dentro de um sistema de significação e de codificação que nos classifica, hierarquiza e socializa - e nós também classificamos, hierarquizamos e socializamos as coisas, nos usos sociais que delas fazemos. A relação é, na perspectiva da antropologia do consumo, dialógica.

A cultura é o lugar em que se realiza o consumo, lição que aprendemos na tradição dos estudos antropológicos que remontam à discussão sobre a dádiva em Marcel Mauss (2007) e ao caráter simbólico indissociável das trocas. Consumo, aqui, tomado como o sistema de significação e comunicação em Douglas e Isherwood (2004), no qual os bens são codificados para estabelecer aproximações e distâncias sociais, mantendo vivas as dinâmicas das sociedades. São os bens materiais que elaboram identidades coletivas e individuais, e, mais ainda, na sociedade de consumo, não resta dúvida de que há uma relação de interdependência entre pessoas, coisas e significados. Por "cultura material", expressão controversa adotada por Daniel Miller para delimitar seus estudos sobre as materialidades, entendemos o conjunto de "coisas", as quais, por fazer parte da cultura, estão intrinsecamente dotadas de significados, que sustentam o sistema de trocas, base do consumo. E tal qual Miller, evitamos subjugar os bens materiais à sua função meramente simbólica ou sígnica, compreendendo que há, neles, um poder de agência sobre os indivíduos. Trata-se de inspirar-se na discussão sobre materialidade e sociedade desenvolvida por Tim Dant (2006): o autor toma de empréstimo a expressão braudeliana "civilização material" e o "processo civilizador" de Norbert Elias para enfatizar que os objetos criados pela civilização tanto constituem como refletem a sua natureza. Para Dant, o valor dos objetos materiais que estão incorporados na vida social não deriva exclusivamente de suas origens na produção, de seus significados atribuídos pelo consumo, de seus usos práticos na vida cotidiana ou de redes associadas com sua emergência como entidades técnicas - ele deriva de tudo isso simultaneamente. E, mais, o autor demonstra a interdependência entre materialidade e sociedade uma vez que os objetos são mediadores das relações humanas, conectando pessoas, ganhando autonomia por meio de ações capazes de regular/controlar os ambientes em que nos encontramos e armazenando memória e informação.

À luz da discussão que propomos neste artigo, acreditamos, sobretudo, que a cultura material é um espaço de transcendência, grosso modo, em que as coisas, em algum momento, podem deixar de servir exclusivamente ao consumo, como parte de seu sistema, cujos significados são públicos e coletivos, e passar a integrar outro sistema, este privado e subjetivo, o que configura uma reconversão de valores e de valorações, as quais, muitas vezes, elaboram novas semânticas, representações e relações dentro de universos particulares alheios 
às prescrições do consumo como espaço de trocas - simbólicas e mercantis. Para tanto, buscamos o contexto do luto como um dos momentos em que ocorre esse fenômeno.

Nesse sentido, entendemos que nem sempre a classificação, a hierarquização e a socialização explicam a relação entre pessoas e coisas, entre coisas e pessoas, quando tal relação se dá em lugar distinto daquele em que residem as trocas simbólicas, especialmente aquelas dadas ao estabelecimento de cercas e pontes em sociedade. Sendo assim, assume-se que a cultura material, nos termos de Daniel Miller, sustenta o consumo, mas o consumo não é capaz de sustentar todas as possibilidades dialógicas da cultura material nas relações entre coisas e pessoas. É nesse sentido que compreendemos, ao seu lado, que os estudos de consumo estão inscritos no campo de estudos da cultura material, porém a cultura material abre possibilidades para um universo mais amplo que o mundo do consumo enquanto espaço público e coletivo da cultura. Ao longo de sua obra, Miller reitera inúmeras vezes que o consumo é uma das chaves para compreender a nossa humanidade. Ao mesmo tempo, demarca que as práticas de consumo incluem processos de construção identitária, mas a eles não se restringem, uma vez que são também uma esfera de produção dessa cultura material.

Essa perspectiva se apoia na premissa de que o contexto da significação, que aqui discutimos a partir do luto e da perda, revela os códigos coletivos e públicos que mapeiam a relação dialética entre as pessoas e as coisas. Mas é justamente o contexto da vida cotidiana que faz emergir os códigos particulares, nem sempre partilhados socialmente, que configuram a interdependência ontológica entre as próprias materialidades das coisas e das pessoas, e não apenas pela representação, pela significação dessa relação. Ou seja, a teoria dialética da objetificação não é uma teoria da representação, mas um processo de criação de novas formas e significados, que por sua vez produzem também novas subjetividades.

Metodologicamente, a contribuição dos estudos de Daniel Miller dedicados à cultura material não é puramente epistemológica e reside sobretudo na abordagem antropológica e etnográfica das relações dialéticas entre pessoas e coisas. A teoria da objetificação, fundamentada em uma compreensão etnográfica da cultura material, transcende tanto a dualidade quanto as hierarquias tradicionalmente atribuídas à relação sujeito/objeto. Sua formulação problematizou o paradigma de um suposto poder de agência dos indivíduos sobre as coisas, dialogando e, por vezes, opondo-se a outras perspectivas teóricas, como as de Jean Baudrillard (I993), que toma os objetos como instrumentos e signos dentro do sistema do consumo, e de Russel Belk (I988), que entende que as coisas são posses (aí incluindo não somente bens materiais, mas também pessoas, lugares, coleções e até mesmo partes de um corpo) que representam extensões de nosso self. 
Essa relação sujeito/objeto, dentro das discussões de Miller, engendra uma série de perguntas, das quais algumas são chave para reelaborar essa dicotomia a partir de uma reflexão sobre o poder de agência: quais são os limites e as possibilidades do poder de agência na constituição do nosso self? E qual o poder de agência de um objeto para ser o que é? Miller questiona a noção de agência como um atributo inerente aos sujeitos e/ou objetos e propõe, com sua teoria da materialidade, um olhar relacional e sempre contextual para a agência.

Outros intelectuais influentes da atualidade também reconhecem o poder de agência dos objetos e se dedicam à superação de dualidades entre pessoas e coisas, como Bruno Latour (I 999) e Tim Ingold (2007).

Latour considera os objetos atores que possuem um tipo de agência que não pode ser separada do mundo social. Em sua concepção, a agência dos objetos é definida socialmente, em contextos de interação entre sujeitos; e os objetos carregam informações do mundo social; isso é o que lhes fornece agência para, também, agir no lugar das pessoas - de modo que em seu entendimento os objetos atuam como representações e não no registro de uma interação dialética entre pessoas e coisas. ${ }^{2}$ Em outras palavras, Latour compreende que a agência dos objetos é aquela que os sujeitos humanos lhes deram. Em contraponto, Miller (2002) usa a objetificação para criar uma teoria da cultura material, e argumenta em prol do reconhecimento da autonomia das coisas, das coisas como sujeitos - ou, como propomos, Miller reconhece a "coisidade" das coisas, mas compreende que a materialidade é sempre o suporte de significados simbólicos definidos contextualmente.

Miller $(1987,2008)$ elabora, ainda, uma reflexão sobre a força da presença das coisas em nossas vidas, ao propor o conceito de "humildade dos objetos", e argumenta que a forma como nos relacionamos com os objetos nem sempre acontece de um modo livremente escolhido. Isso significa dizer que a força dos objetos muitas vezes reside no fato de que eles não são notados, ou seja, precisamente porque "não os vemos", no sentido de não estarmos conscientes de sua presença, é que são tão poderosos. Esses objetos se inscrevem em nossas rotinas de uma forma normativa, definindo situações e, como explica Miller, definindo a nós mesmos - de tal modo que o que somos não se restringe à materialidade dos nossos corpos e à nossa consciência: estamos também nas coisas.

Os contextos de luto são sintomáticos para pensar sobre a humildade dos objetos e sua relação com o poder de agência como definido por Miller. As coisas que muitas vezes são silenciadas e se inscrevem em situações rotineiras normativas na vida de alguém potencialmente podem adquirir um novo significado com a morte dessa pessoa. Por exemplo, quando se passa a usar um relógio de uma pessoa amada que morreu, torna-se quase imperativo não sair de casa sem esse relógio, de tal modo que esse esquecimento pode gerar culpa. O luto, então, confere às coisas novo poder de agência: coloca os objetos em 
evidência, e a consciência da presença desses objetos é uma forma de fazer com que a pessoa querida permaneça presente.

Assim como Miller, Tim Ingold argumenta que as coisas são tanto materiais quanto culturais. Contrastando, porém, com a perspectiva etnográfica e dialética proposta por Miller, Ingold (2007, 2010) propõe uma abordagem experimental, caracterizada como física e ambiental, ao enfatizar as propriedades materiais dos objetos ou sua matéria (em inglês, matter). Essas propriedades, por sua vez, não são qualidades fixas, mas têm um caráter processual e relacional (Ingold, 2007) porque estão em interação com o mundo material que as circunda. Para ele, o poder de agência reside justamente na materialidade, de tal modo que "as coisas estão na vida em vez de a vida estar nas coisas"3 (Ingold, 2007 , p. I 2). As coisas estão vivas e ativas não porque possuem um "espírito" ou uma vida, mas porque sua matéria, aquilo que as compõe fisicamente, é continuamente significada pelos contextos de circulação em que essas coisas se inscrevem ou para os quais são arrastadas, nas palavras de Ingold. Esses contextos podem definir tanto a dissolução e o fim das coisas quanto sua regeneração. Nisso, segundo o autor, reside a ontologia das coisas.

O que diferencia Miller de outros teóricos, em particular Latour e Ingold, que, como vimos, também se dedicam a pensar a questão da materialidade, é o fato de Miller sempre buscar mais os significados das coisas do que a "coisidade" em si. Ou seja, ele dialoga mais com a antropologia do consumo do que Bruno Latour e Tim Ingold, que no limite olham principalmente para a fisicalidade dos objetos.

Em outra publicação, Stuff (Miller, 2010), que em português foi traduzida como Trecos, troços e coisas (Miller, 20I3), Miller (2010, p. 209) afirma que "coisas (no original stuff) são tanto uma questão de morte quanto de vida". Na versão em português dessa frase a palavra stuff foi traduzida como treco, que consideramos imprecisa, e isso aparentemente confere uma nova dimensão analítica (em alguns dicionários inglês-português a tradução para stuff é "coisa"). O que queremos reter nesta reflexão, contudo, é o caráter contingencial das coisas atravessando contextos de vida e morte de pessoas. Miller (20I0, p. 2 I7) lembra que existe uma variedade de formas pelas quais as sociedades se separam das coisas e também as retêm e ressignificam.

Raramente, em nossa cultura, guardamos como lembrança objetos que remetem à morte ou ao processo de alguma doença degenerativa que causou a morte de entes queridos. O que nos interessa guardar são memórias felizes dos nossos familiares e amigos. Por isso guardamos fotos, objetos que faziam parte se sua rotina de trabalho, que foram importantes em alguma ocasião especial, como a celebração de um casamento, aniversário, alguma homenagem, uma viagem especial, objetos associados a uma rotina de atividades protagonizadas de forma saudável pela pessoa querida. Os exemplos podem se estender indefinidamente. Outro ponto importante nessa discussão, e que Miller 
(20I0, p. 2I7) observou em sua pesquisa, diz respeito a pessoas de gerações mais antigas que costumavam definir o que deixariam de herança para seus familiares, como se esperassem que os objetos selecionados pudessem ajudar seus descendentes a se tornar mais do que elas gostariam que fossem. A esse respeito Miller (20I0, p. 2I7) cita como exemplo pais religiosos que podem deixar objetos sagrados como herança para seus filhos na expectativa de que, após sua morte, esses objetos garantam maior grau de observância religiosa aos seus descendentes.

A seguir discutimos a relação emblemática entre luto e materialidade refletindo a partir das propriedades materiais das coisas mergulhadas em um contexto específico de perdas na história de Elia, personagem descrita em The comfort of things (Miller, 2008), e de Walter Benjamin, em seu processo de reorganização de uma nova vida, descrito em "Desempacotando minha biblioteca" (I987).

\section{A VIDA E A MORTE DAS MATERIALIDADES}

Para melhor defender a premissa de que a cultura material é maior do que o consumo ou a ele anterior, expressão e termo aqui tomados como categorias de pensamento ou campo teórico, cabe-nos buscar na obra de Daniel Miller alguma referência etnográfica que nos ancore de volta ao solo fértil da vida cotidiana. E é aqui que entra Elia, um dos 30 portraits já mencionados.

Elia é uma mulher que vive sozinha em uma casa repleta de objetos que contam histórias. Elia é, aliás, segundo o autor, uma ótima contadora de histórias. Gesticula tanto, que é possível quem a escuta visualizar mentalmente a forma das pessoas de sua família que ela constantemente rememora e que já morreram. A avó, a tia, o tio, a mãe, todos estão presentes nas histórias e nos objetos da casa de Elia; a presença mais forte, contudo, é a do avô, com quem ela conversa e a quem pede conselhos, às vezes apoiada na mesa que ele fez com suas mãos. No armário, que Miller associa a uma espécie de museu, há roupas que foram costuradas por sua tia querida, usadas por sua mãe e que, volta e meia, saem para passear ou dançar no corpo de Elia. As joias também têm seu lugar, mas nada, nada se compara às roupas.

A descrição sensível e densa de Elia feita por Miller estimula a reflexão sobre perda, sofrimento e luto. Mas não é só isso. Principalmente, faz pensar sobre como se constroem relacionamentos, nos termos do autor, com os objetos das pessoas que morreram, e com elas próprias, especialmente aquelas que são mais importantes ou mais amadas. Ao contrário do que poderíamos pensar de forma mais apressada, para Miller a prática de guardar coisas de pessoas que já morreram não trata de substituir a pessoa que está ausente por objetos que a ela pertenciam, como uma metonímia. As roupas que Elia guarda tão respeitosa e carinhosamente, de acordo com Miller (2008), tampouco são meras "representações" das pessoas que se ausentam, elas são mediadoras que transferem substância e emoção entre as pessoas, vivas e mortas. 
As pesquisas de Daniel Miller buscam sempre a "objetificação" por trás da relação que as pessoas estabelecem com as coisas. Nesse caso, a objetificação está na "estética" do interior das casas que visitou, ou seja, na configuração de valores, sentimentos e experiências humanas, mais do que do sistema repetitivo, presente no ordenamento das coisas por meio da decoração, da disposição racional dos objetos nos espaços. No caso de Elia, sua estética pode ser sintetizada em "relacionamentos, coisas e emoções". Nas palavras do antropólogo, "Os objetos armazenam e possuem, inspiram e expiram as emoções com as quais foram associados" (Miller, 2008, p. 36). Emoções associadas, é claro, com as experiências vividas junto às pessoas que, no caso de Elia, fazem parte de sua história na condição de neta, filha, sobrinha, alguém que tinha uma família e que, agora, vê-se solitária no mundo.

O ordenamento que damos às coisas e a relação que estabelecemos com essa ordem é uma forma de encontrar algum conforto existencial naquilo que é familiar e repetitivo - daí o "conforto das coisas". A perda material, ou a morte, seria, então, o vento forte que tira tudo do lugar, que desordena, que desafia o controle sobre a ordem. É o "ficar sem chão", perder o suporte material que nos sustenta, é viver o susto, revoltar-se, recolher-se, conformar-se e, depois, tentar encontrar uma nova ordem ou uma nova "estética" para a vida sem a pessoa ou o objeto que se perdeu, que ficou para trás.

Miller (2008) observa que a cultura material tem papel central nesses processos de perda e de luto, que se revelam, no caso de Elia, por meio de três tipos de objeto: o cemitério, as roupas e as joias. Para o antropólogo, "O instrumento de luto mais adequado e bem-sucedido é a coleção de roupas, o mais difícil, o conjunto das joias, e o mais pungente é o cemitério" (Miller, 2008, p. 42).

O cemitério, observa o autor, é onde Elia ainda pode dar vazão ao seu sentimento de dor. É um lugar de manutenção e dedicação aos mortos de sua família. Por ter origem grega, trata-se, tradicionalmente, de um jardim com flores e, como tal, deve ser permanentemente cuidado. É no cemitério que ela visita seus avós, senta-se sobre o túmulo, conversa e conta as boas novas.

As roupas, ele prossegue, são porosas: inspiram e expiram emoções que vinculam Elia à sua tia e à sua mãe. Elas não duram para sempre, mudam, desbotam e carregam algo da corporalidade de quem as usou. São ressocializadas quando vai a uma festa ou aos bailes em que dança livremente. Quando doadas, destinam-se apenas a quem as irá reverenciar: "Tais coisas levam os mortos e os vivos a um estado de imediatismo um com o outro. Assim, graças às roupas, ela pode servir a mãe novamente: 'você encontra formas de trazê-la para espaços e eventos sociais e eventos familiares e de lhe proporcionar bons momentos'” (Miller, 2008, p. 42). O relacionamento que ela estabelece com essas roupas permite que Elia assimile, de forma recorrente, um pesar que foi vivido e depois superado pelo próprio processo do luto. No guarda-roupas guardam-se, também, as lágrimas que mantêm vivo, como os próprios vestidos que ali residem, o sentimento afetuoso para com sua mãe e sua tia. 
As joias, que pertenceram à sua mãe, determinam outro tipo de relacionamento com Elia. Segundo Miller (2008, p. 4I), as joias "resistem à humanidade". Sendo materialmente imutáveis, permanecem como objetos mais rígidos, menos "porosos", ou seja, não têm vocação igual à dos vestidos, pois nada há, nos anéis e braceletes, de resquícios de um corpo que um dia os usou. A relação que esses objetos estabelecem com a mãe de Elia é mais "abstrata” (Miller, 2008, p. 43). Há, porém, outro aspecto das joias para o qual o autor chama atenção: seu valor monetário. A joia ainda é uma mercadoria e, como tal, estará sempre ancorada em seu vínculo também abstrato com outro tipo de valor que, ali, não interessa à filha devotada. Pondera-se, aqui, que tal análise sobre as joias pode ser refeita à luz das mesmas considerações sobre "objetificação" operadas por Miller. Em termos de temporalidade e manuseio, joias possuem substância distinta daquela dos materiais mais "porosos"; é interessante recordar, porém, que, embora resistentes, elas também são transformadas, desgastadas e alteradas pela ação de pessoas, e passam a carregar em si essas alterações. Afinal, joias podem ser refeitas, gravadas com datas, iniciais e outras informações, fracionadas e dadas em herança, recombinadas ou recompostas, desgastadas pelo uso constante e pelas próprias práticas de manutenção, como o uso de abrasivos e polimentos, de maneira que podem demonstrar mutabilidades características de sua relação com as pessoas, que é a pátina que as singulariza (McCracken, 2010).

Considerando os exemplos das roupas e das joias, retomemos o que nos ensinou Igor Kopytoff (2010, p. I09) a respeito da "singularização" dos objetos:

As sociedades complexas têm um evidente desejo de singularização. Grande parte desse desejo é satisfeita individualmente pela singularização particular, baseada em princípios tão corriqueiros quanto os que determinam o destino de grandes patrimônios, ou de chinelos velhos - a longevidade do relacionamento de algum modo os assimila de tal forma à pessoa que torna impensável uma separação entre eles.

Por vezes esse desejo humano assume as propriedades de uma fome coletiva, que se evidencia nas respostas generalizadas a renovadas formas de singularização. Coisas velhas, como latas de cerveja, caixas de fósforo e revistas em quadrinhos, de repente assumem valor, e passa a ser vantajoso colecioná-las; assim, elas passam da esfera do que é sem valor para a esfera do que é singularmente caro [...] Tal como entre os indivíduos, grande parte da singularização coletiva é alcançada pela referência à passagem do tempo. Como mercadorias, os carros vão perdendo valor conforme ficam mais velhos, mas, quando chegam mais ou menos à idade de 30 anos, começam a transitar para a categoria de antiguidades e passam a ganhar valor com cada ano que passa.

As roupas que Elia preserva em seu guarda-roupa estariam, sob esse prisma, singularizadas pelo seu próprio desejo de preservar, também, o relacionamento com quem um dia as vestiu. E tal singularização se dá, exatamente, pelo que Miller chamou de porosidade, propriedade que favorece o (re)encontro de pessoas por meio das coisas. Trata-se, sobretudo, de uma singularidade de cará- 
ter individual, já que não depende do circuito mercantil nem da esfera pública para ter sentido e valor para Elia. As joias, dentro do sistema simbólico do consumo, vinculam-se a ideais de preciosidade e luxo, e quando associadas à passagem do tempo, como aponta Kopytoff, estão muito mais próximas de uma singularidade de caráter coletivo do que as roupas velhas (desde que usadas por pessoas comuns e não por celebridades). Enquanto as joias vão ganhando valor à medida que passam a transitar por critérios objetivos como antiguidade, as roupas, ao contrário, vão perdendo valor. Se há algum espaço para as trocas simbólicas, elas estariam muito mais favorecidas com relação às joias do que com relação às roupas usadas e já gastas do "museu" de Elia. As roupas de sua tia e de sua mãe um dia foram mercadorias e deixaram de ser por escolha própria, mas poderiam ser novamente postas em circulação em algum charmoso e barateiro brechó de Londres. As joias, por outro lado, carregam, em sua imutabilidade, uma vocação mercantil muito mais poderosa, pautada exatamente no caráter coletivo de sua singularidade, cuja simbologia é traduzida por aspectos mercantis, podendo ser vendidas a preço alto. Ainda assim, Elia tem poder de decisão, esvaziando, se assim desejar, o anel e o bracelete de qualquer valor que não seja o do sentimento de amor e do relacionamento que mantinha com sua mãe, deixando-os fora da esfera das trocas mercantis.

A mesa, as roupas, o cemitério, as joias e tantos outros objetos que preenchem a vida de Elia, dentro do ordenamento por ela construído, tornam cotidianos, novamente, os relacionamentos que, um dia, tiveram lugar em sua história. Os objetos que ela guarda expressam um perene sentimento pelas pessoas que mais amava e por tudo o que perdeu ao longo de sua trajetória: "Ela naturalmente reúne diferentes experiências de perda: a morte de sua mãe e tia, filhos crescendo e saindo de casa, seu divórcio, ela mesma envelhecendo. Todas essas coisas exigem alguma forma de luto" (Miller, 2008, p. 4I).

Tomemos, agora, outra situação de "luto", aquela que diz respeito à perda não de pessoas, mas de coisas. Situações vividas, por exemplo, por refugiados, migrantes, solteiros que se casam, casados que se separam, famílias que se mudam de cidade, pessoas que saem de grandes espaços e passam a ocupar pequenos espaços. Rupturas forçosas, tal qual a morte, entre as pessoas e as coisas que possuem. O cachorro, a coleção de discos de vinil, os livros, os suvenires comprados em viagens inesquecíveis, o sofá e tudo o mais que entra na partilha dos bens de um casal que se divorcia, todos esses objetos fazem parte de uma "estética", como sugere Miller (2008), construída a dois. De repente, esse ordenamento dos objetos dentro de casa, que garantia o "conforto das coisas", é invadido pelo vento de verão. Hora de viver o luto, ficando imóvel, depois raivoso, em seguida profundamente triste e vazio, para então se resignar e reconstruir uma nova ordem para a vida cotidiana.

O luto é uma transformação. Esse luto que não acontece pela morte de uma pessoa, mas por uma situação ou combinação de situações que desesta- 
biliza a permanência e os significados dos objetos, desestabiliza também o conforto das coisas das nossas casas e das nossas vidas, e nos coloca muitas questões sobre objetificação, agência e materialidade.

Em Home possessions, livro organizado por Miller, o texto de Jean-Sébastien Marcoux (200I) inicia com a citação de um ensaio bastante conhecido escrito por Walter Benjamin em I93 I, um ano após seu divórcio. Nele, Benjamin (I 987, p. 227) nos conta: "Estou desempacotando minha biblioteca", e prossegue narrando que "os livros ainda não estão nas estantes e, portanto, não foram tocados pelo suave tédio da ordem". Benjamin convida quem lê a juntar-se a ele na desordem de sua mudança e experimentar a alegria de um colecionador que reencontra seus livros guardados nas caixas já há alguns anos, sem ver a luz do sol. E prossegue dizendo que aparenta estar falando de sua biblioteca, mas na realidade fala de si mesmo.

Diferente do relato sobre Elia, que se trata de uma etnografia feita por Miller, Benjamin escreve em primeira pessoa um relato sobre si mesmo e sobre sua relação com os livros e seus significados. Acessamos esse texto com um olhar histórico-etnográfico sobre Benjamin e sua biblioteca na tentativa de compreender, a partir das noções discutidas por Miller, o poder de agência dos objetos em um contexto de mudança de vida. A noção de luto, aqui, perpassa a ideia de ruptura, desestabilização e perda ou separação das materialidades.

Enquanto vai desencaixotando sua biblioteca, Benjamin relembra uma série de situações, pessoas e lugares. Lembra contextos de aquisição de alguns desses livros, memórias familiares, das casas onde morou, dos volumes que herdou e daqueles da infância que foram perdidos. Em seu ensaio, Jean-Sébastien Marcoux recorre a Benjamin para discutir o papel desempenhado pelas posses móveis (mobile possessions) na conformação de uma "memória em movimento". Benjamin não se dedicou ao estudo da cultura material, mas compreendia bem a relação dialética entre pessoas e coisas. Compreendia que a relação com seus livros era muito mais do que uma relação funcional de leitura, estudo e acesso à informação, e não por acaso usa palavras como "paixão", "memória" e "lembrança" em seu texto.

Embora Benjamin focalize, em primeiro plano, o ato de colecionar livros, ele também nos dá acesso a outros caminhos de reflexão. Percorrendo, ao lado de Miller, as trilhas do consumo e da cultura material, encontramos em Benjamin a narrativa de uma experiência sensível que evidencia como as memórias, lembranças e emoções evocadas pelo objeto livro configuram uma trajetória de sentimentos marcados pela mobilidade geográfica, pelas conquistas e também pelo que passou, pelo que se perdeu e pelas incertezas do que virá.

Sentimentos contraditórios emergem enquanto Benjamin desempacota seus livros. Se por um lado ele expressa alegria por reencontrar os volumes outrora guardados em caixas, por outro também hesita e afirma que "nada pode realçar mais a operação de desempacotar do que a dificuldade de concluí-la" 
(Benjamin, I987, p. 234). Nesse contexto a crítica à ordem, no primeiro parágrafo do ensaio, pode ser compreendida não simplesmente como uma dificuldade em organizar pragmaticamente os livros na estante, mas como hesitação em reposicionar esses objetos em uma nova vida, em construir para eles uma "nova estética" e, nesse processo, se deparar com sua "porosidade", como definiria Miller. Existe mesmo uma dualidade presente nesse processo, em que o "conforto das coisas", aparentemente recuperado pelo reencontro com seus livros, não parece descolado de um certo desconforto existencial em reordená-los em uma vida nova e imponderável. Podemos, aqui, recorrer a uma leitura histórica que não está integralmente descrita no ensaio de Benjamin, mas que sabemos ser indissociável dele. O recente divórcio, as dificuldades de viver na Alemanha no período entre guerras, a crescente ascensão do nazismo no país e a perseguição às pessoas de origem judaica e aos intelectuais são fatores que obrigariam Benjamin, no ano seguinte à arrumação da biblioteca em sua nova casa, a se mudar novamente, separando-se mais uma vez de seus livros e seguindo para o exílio forçado na Espanha.

A porosidade dos livros de Benjamin, de forma análoga à das roupas de Elia, expressa a relação entre perdas, transformações, permanências e continuidades. Os livros dão acesso ao passado e suas memórias, são mediadores de relações com outras pessoas, lugares e temporalidades, e isso constitui sua singularidade. Os exemplos de Elia e Benjamin, distantes no tempo e ancorados em contextos específicos, devem ser também compreendidos, nos ensina Miller, a partir dos padrões específicos dessas relações, bem como do poder de agência das materialidades em cada contexto.

Em certo ponto da arrumação, dois volumes encadernados com papelão desbotado caem nas mãos de Benjamin. Ele nos explica tratar-se de dois álbuns de figurinhas que sua mãe colecionava quando criança e que foram herdados por ele: "são as sementes de uma coleção de livros infantis que ainda hoje cresce constantemente ainda que não seja no meu jardim" (Benjamin, I987, p. 234). Podemos supor que essa menção seja uma referência a seu filho, de quem Benjamin estava separado.

Os álbuns da infância de sua mãe levam Benjamin (I987, p. 234) a refletir sobre o significado dos livros como objetos herdados: "a herança é maneira mais pertinente de formar uma biblioteca", pois impõe um sentido de responsabilidade particular, associado ao orgulho da posse. Aqui, retomamos uma atribuição de valor aos objetos herdados que guarda semelhanças com o exemplo de Elia, no sentido de a transmissibilidade da coisa herdada já ser um traço de distinção per se. Mas a porosidade dos livros herdados talvez os posicione em um lugar intermediário entre as roupas e as joias de Elia. Embora também sejam objetos móveis, reverenciáveis e sujeitos ao desgaste, os livros não "saem para passear" e não são ressocializados da mesma maneira que as roupas. 
Ao final do ensaio Benjamin (I987, p. 235) complexifica sua reflexão sobre posse e responsabilidade, e argumenta que "a posse é a mais íntima relação que se pode ter com as coisas". Para explicar essa afirmação, ele recorre à metáfora dos livros que edificam uma morada, como se fossem tijolos, dentro da qual o colecionador desaparece. Com esse olhar Benjamin expressa a concepção de si mesmo pelo processo de objetificação e do poder de agência dos objetos em sua capacidade de também nos possuir.

\section{CONSIDERAÇÕES FINAIS}

Os dois tipos de luto que aqui sugerimos, de pessoas e coisas, decorrentes portanto de perdas materiais, estarão sempre conectados. Quando perdemos uma pessoa com quem convivemos, com ela morre uma ordem que rege a vida cotidiana, já que, como vimos, tal ordem se dá pela forma como construímos o nosso mundo material ao redor. O processo doloroso do luto envolve, primordialmente, dar destino às coisas que ficaram sem dono. Envolve também estabelecer um novo ordenamento ou uma nova "estética", como quer Miller, às nossas casas, buscando alcançar novamente, de outro modo, o conforto proporcionado pelas coisas. Por outro lado, quando perdemos também forçosamente algumas das coisas que ordenam a nossa vida, quando temos que as deixar para trás, deixamos também pessoas, memórias, relacionamentos, projetos de vida, sofrimentos, experiências, enfim, uma vida pregressa que morre junto com aquele arranjo. Ainda que tenhamos a oportunidade de escolher o que colocar na mala, essa seleção esvazia-se do sentido anterior, posto que a nova casa exigirá, também, uma nova "estética", nos termos de Miller (2008).

Visto pelo ângulo da cultura material, o luto é o processo solitário, pelo qual lidamos com a ausência física das coisas, dos corpos, do ordenamento cheio de significação que nos situa no mundo. É quando percebemos o quanto aquela pessoa ou aquelas coisas - se é que podemos, agora, as separar - faziam parte de nós, o quanto estavam impregnadas no que somos. É, também, valorar o mundo de um modo único e não estar disposto a trocar nada com ninguém.

Visto pelo ângulo do consumo, o luto é a "expressão obrigatória dos sentimentos" (Mauss, 2005). Na perda de uma pessoa, interessa mais o preto ou o branco das roupas na hora da última despedida, ou o bom senso de saber escolhê-las para evitar reprovação social. Na perda de algumas coisas, é a oportunidade de renovar o armário, os móveis, o carro, mostrar para todos o quanto somos resilientes. É, também, tornar a dor pública, divulgá-la nas redes sociais online e nas conversas com os amigos, marcando um novo status de "viúva" ou "divorciada".

De um modo ou de outro, e em geral dos dois ao mesmo tempo, estaremos sempre buscando ordenar o nosso mundo por meio das materialidades, seja de qual for o ponto de partida. Se o consumo, no luto pelas pessoas ou pelas coisas, abre espaço para coisas novas em uma "vida nova", esta só será 
dotada de sentido à medida que a dinâmica da cultura material entrar novamente em ação, proporcionando, no "conforto das coisas", o ordenamento da vida, dos sentimentos e das emoções. Até que um novo vento chegue e bagunce tudo outra vez.

Recebido em Io/3/2020 | Revisto em I9/8/2020 | Aprovado em 7/9/2020

Cláudia Pereira é professora e pesquisadora do Programa de PósGraduação em Comunicação da PUC-Rio. Em 20I8, realizou pesquisa como investigadora visitante no ICS - Instituto de Ciências Sociais da Universidade de Lisboa, no campo dos estudos das juventudes e da cultura material. É líder do grupo de pesquisa JuX - Juventudes Cariocas, suas culturas e representações midiáticas. Em 2020, organizou o livro Brazilian youth: global trends and local perspectives.

Fernanda Martinelli é professora e pesquisadora no Programa de PósGraduação em Comunicação da UnB, e visiting scholar na Brown University entre 2019-2020. Coordena o grupo de pesquisas Consumo e Cultura Material e trabalha com temas como moda, pirataria e alimentação. Atualmente coordena o projeto Territories of flavors, em que discute o pensamento culinário como dispositivo metodológico. É coautora dos capítulos de livros "Comida como afeto" e "Rebuilding lives: itinerancies, life projects and field of possibilities of migrant youth in Brazil", entre outras publicações. 


\section{NOTAS}

I No original, People exist for us in and through their material presence (Miller, 2008, p. 286). Nessa e nas demais citações de originais em idiomas estrangeiros, a tradução é nossa.

2 Um exemplo heurístico a esse respeito é a conhecida discussão de Latour (I999) em que o autor propõe que uma pessoa em posse de uma arma não esteja sujeita a um objeto. Conforma aí, em sua opinião, um novo híbrido, que é a combinação pessoa/arma. Esse híbrido é que seria a causa de qualquer possível efeito, como se pessoa/arma conformasse então uma nova entidade. A crítica de Miller, nesse caso, seria a de uma compreensão incompleta da agência por parte de Latour, que ignora justamente o papel da agência da cultura material.

3 No original, things are in life rather than that life is in things.

\section{REFERÊNCIAS}

Appadurai, Arjun (I986). Introduction: commodities and the politics of value. In: The social life of things: commodities in cultural perspective. Cambridge: Cambridge University Press, p. 3-63.

Baudrillard, Jean. (I993). O sistema dos objetos. São Paulo: Perspectiva.

Belk, Russel. (I988). Possessions and the extended self. Journal of Marketing Research, I5/2, p. 72-95.

Benjamin, Walter. (1987). Desempacotando minha biblioteca. In: Rua de mão única. Obras Escolhidas, v. 2. São Paulo: Editora Brasiliense, p. 227-235.

Dant, Tim. (2006). Material civilization: things and society. British Journal of Sociology, 57/2.

Douglas, Mary \& Isherwood, Baron. (2004). O mundo dos bens. Rio de Janeiro: UFRJ.

Ingold, Tim. (2010). Bringing things to life: creative entanglements in a world of materials, realities. Working Paper, I5.

Ingold, Tim (2007). Materials against materiality. Archaeological Dialogues, I4/I, p. I-38. 
Kopytoff, Igor. (20I0). A biografia cultural das coisas: a mercantilização como processo. In: Appadurai, Arjun (org.). A vida social das coisas: as mercadorias sob uma perspectiva cultural. Niterói: Editora da Universidade Federal Fluminense, p. 89-I2 I.

Latour, Bruno. (I999). Pandora's hope: an essay on the reality of science studies. Cambridge: Harvard University Press.

Marcoux, Jean-Sébastien. (200I). The refurbishement of memory. In: Miller, Daniel (org.). Home possessions: material culture behind closed doors. Oxford: Berg, p. 69-86.

Mauss, Marcel. (2007). Sociologia e antropologia. 2 ed. São Paulo: Cosac \& Naify.

Mauss, Marcel (2005). A expressão obrigatória dos sentimentos. In: Ensaios de sociologia. São Paulo: Perspectiva, p. 325-335.

McCracken, Grant. (2010). Cultura \& Consumo. Rio de Janeiro: Ed. Mauad.

Miller, Daniel. (20I3). Trecos, troços e coisas. Rio de Janeiro: Zahar.

Miller, Daniel. (2010). Stuff. Cambridge: Polity Press.

Miller, Daniel. (2008). The comfort of things. Cambridge: Polity Press.

Miller, Daniel. (2002). Teoria das compras: o que orienta as escolhas dos consumidores. São Paulo: Nobel.

Miller, Daniel. (1987). Material culture and mass consumption. Oxford: Basil Blackwell.

Miller, Daniel \& Parrot, Fiona (2009). Loss and material culture in South London. The Journal of the Royal Anthropological Institute, I5/3, p. 502-519.

Pais, José Machado. (I993). Culturas juvenis. Lisboa: Imprensa Nacional-Casa da Moeda.

Sahlins, Marshall. (2003). Cultura e razão prática. Rio de Janeiro: Jorge Zahar. 
Palavras-chave

Daniel Miller; cultura material;

pessoas; coisas;

luto.

\section{AS PESSOAS, AS COISAS E AS PERDAS: PERSPECTIVAS DA CULTURA MATERIAL E DO CONSUMO NOS ESTUDOS DE DANIEL MILLER}

\section{Resumo}

Na sociedade de consumo, as relações entre pessoas, coisas e significados se estendem por territórios vastos e diversificados. Neste artigo, enfatizamos a construção ontológica que se dá entre pessoas e coisas, coisas e pessoas, para além das trocas simbólicas, coletivas e públicas, promovida pelo consumo. Propomos uma reflexão sobre as relações que pessoas estabelecem com coisas em situações de luto, expressão que utilizamos para nos referir não somente ao sentimento associado à morte de pessoas, mas, de modo amplo, ao sentimento de perda de materialidades. Metodologicamente, a contribuição de Daniel Miller está na abordagem antropológica e etnográfica das relações dialéticas entre pessoas e coisas, e entre coisas e pessoas, que discutimos aqui a partir de conceitos como "objetificação", "humildade dos objetos" e "poder da agência".

PEOPLE, THINGS AND LOSSES: PERSPECTIVES OF MATERIAL CULTURE AND CONSUMPTION IN DANIEL MILLER'S STUDIES

Keywords

Daniel Miller; material culture; people; things; mourning.

\section{Abstract}

In the consumption society, the relationships between people, things and meanings extend across vast and diverse territories. In this article, we emphasize the ontological construction that occurs between people and things, reciprocally, beyond symbolic, collective and public exchanges in consumption practices. We reflect upon relationships that people establish with things in contexts of mourning. By mourning, we refer not only to the feeling associated with someone's death but broadly, to the feeling of loss of materialities. Methodologically, Daniel Miller's contribution lies in the anthropological and ethnographic approach to the dialectical and mutual relationships between people and things, which we discuss here departing from concepts such as "objectification", "humility of objects" and "agency". 